\title{
Formações discursivas na EJA: posicionamentos discursivos de professores de língua inglesa $^{1}$
}

\author{
Natália Costa Leite* \\ Maralice de Souza Neves**
}

\begin{abstract}
Resumo
Ancorado nos pressupostos da Análise do Discurso Franco-Brasileira (ADF), este artigo objetiva analisar os efeitos de sentido mobilizados pelos professores sobre o projeto EJA e o ensino de língua inglesa. Em nossas análises, pinçamos diversos significantes que caracterizaram a EJA como um espaço menor ou periférico. Nomeamos tais regularidades como FD do Conformismo. Já a FD da Ruptura sinalizou um corte nesses sentidos (pre)vistos e apontou para a produção de outros (não)saberes e novas/outras memórias perante o aluno e o ensino de Língua Inglesa.

Palavras-chave: Educação de Jovens e Adultos; Ensino de Língua Inglesa; Representações; Análise do Discurso; Psicanálise
\end{abstract}

\section{Discursive Formations of EJA: discursive positions of English teachers}

\begin{abstract}
Anchored on the assumptions of the French-Brazilian Discourse Analysis (ADF, in Portuguese), this paper aims to analyze the effects of meaning mobilized by teachers on the project EJA and English teaching. In our analysis, we gathered several signifiers that characterized the EJA as a smaller or peripheral space. We named these linguistic regularities as DF of Conformity. On the other hand, the DF of Rupture has signaled a break in these (fore)seen directions and pointed to the production of other (non) knowledge and new/other memories towards the student and the English Language Teaching.

Keywords: Education of Young and Adults; English Language Teaching; Representations; Discourse Analysis; Psychoanalysis.
\end{abstract}

\section{Introdução}

Nesse trabalho, pretendemos abrir espaço para reflexão sobre o projeto EJA, assim como os dizeres que o atravessam, sobretudo no que se refere ao ensino de inglês como língua estrangeira, e acabam delineando as representações de professores e alunos. As pesquisas concernentes ao projeto EJA produzidas nas universidades não possuem volume significativo e nem pluralidade que possam suprir a demanda por investigações voltadas à educação para jovens e adultos em cursos de formação de professores e cursos de formação continuada. Machado (2000) alerta que "há um desafio crescente para as universidades no sentido de garantir/ampliar os espaços para discussão da EJA, seja nos cursos de graduação e pós-graduação, [seja na] extensão" (MACHADO, 2000, p.16).

Ao levantarmos o histórico do projeto EJA no país, percebemos que as decisões, direcionamentos e políticas públicas passaram por inúmeras rupturas e se mostraram inexoravelmente relacionadas aos interesses políticos de uma época (MASCIA, 2011). O conjunto de memórias ou o

\footnotetext{
*Endereço Eletrônico: nataliacostaleite@uol.com.br

*** Endereço Eletrônico: maraliceneves@ufmg.br
}

arquivo $^{2}$ (FOUCAULT, 1987) produzido sobre a EJA é formado por complexos movimentos (leis, encontros, movimentos coletivos, práticas), mas também passaram por diversos momentos de silenciamento no campo político e social. Esses movimentos que historicizam a EJA no país concorrem para construir as discursividades sobre a EJA - discursividades essas que incidem sobre os processos de constituição identitária dos professores desses cursos.

Tendo como base teórica a análise de discurso franco-brasileira, nosso objetivo neste artigo é apresentar uma análise das representações de professores de língua inglesa que atuam na EJA, na cidade de Belo Horizonte, considerando a ordem do imaginário que configura o modo de ser do professor, ou seja, a sua identidade profissional (ANDRADE, 2008). Faremos, primeiramente, um percurso que colocará em relevo as condições de produção das discursividades sobre o projeto EJA e sua significância na compreensão dos fatos linguísticos que serão analisados posteriormente. Em seguida, apresentaremos a metodologia de formação do corpus e de descrição dos participantes da pesquisa, dando destaque para suas representações por nós 
tomadas como comportando elementos de ordem inconsciente, composta de dizeres do social, mas também singulares. Finalmente, buscaremos desvelar a trama discursiva através de nossos gestos de interpretação (ORLANDI, 1996) de alguns dos recortes do corpus.

\section{Das condições de produção}

A observação das condições de produção é necessária para os gestos de interpretação empreendidos porque traz elementos externos à superfície linguística e os relaciona com a produção de sentidos em um dado recorte. Propomos uma análise que não se limite à matéria própria do discurso, mas que busque regularidades exteriores, não-discursivas. Interessam-nos, portanto, as práticas sociais, políticas e econômicas realizadas a partir de um recorte histórico e que invariavelmente causam impacto nas discursividades produzidas.

$\mathrm{O}$ conceito de condição de produção apresentado pela analista de discurso Eni Orlandi (2002) objetiva considerar um recorte de significação mais amplo e que extrapola os sentidos estritos de um contexto imediato para abarcar efeitos de sentido que se (con)formam pelas vias do simbólico e do imaginário através do trabalho sócio-histórico. A tarefa de interpretação do analista de discurso é, através da oferta da palavra, escutar além das evidências e ainda reconhecer que "todo enunciado é intrinsecamente suscetível de tornar-se outro, diferente de si mesmo, se desloca[ndo] discursivamente de seu sentido para derivar para um outro" (PÊCHEUX, 2006, p. 53).

$O$ analista de discurso, portanto, ao manipular os fatos linguísticos, se depara com o desafio de operar (n)os limites da interpretação e, para isso, precisa de instrumentos teórico-analíticos que sugiram caminhos na consideração do invisível, do imprevisível e do não-dizível. Nesse sentido, as considerações de Michel Foucault no livro $A$ arqueologia do Saber ([1969] 1987) nos oferecem vias teórico-metodológicas uma vez que para Foucault não é possível desvincular o arquivo das suas condições de apropriação e de utilização.

O processo arqueológico (FOUCAULT, [1969] 1987) não almeja resgatar o baú dos discursos proferidos a respeito de temas específicos e nem empreender uma promoção científica de toda memória histórica e discursiva produzida, mas antes, "interrogar o já-dito", reconhecer a relação existente entre essa memória e os enunciados dos sujeitos analisados e, assim, promover espaço para a (re)atualização dos sentidos. Para o autor, os discursos são retomados no nível dos enunciados e sempre fazem parte de uma série ou conjunto nãoneutros ou casuais. $\mathrm{O}$ enunciado é

uma função que pertence, exclusivamente, aos signos, e a partir da qual se pode decidir, em seguida, (...) se eles [os signos] 'fazem sentido' ou não, segundo que regra se sucedem ou se justapõem, de quê são signos, e que espécie de ato se encontra realizada por sua formulação (oral ou escrita) (FOUCAULT, 1987, p. 98).

Faz-se possível, portanto, a existência de duas enunciações que comportam o mesmo enunciado. $\mathrm{O}$ enunciado pode ser repetido indefinidamente por ser esse agrupamento de signos, porém não será alcançado da mesma maneira através dos tempos. O enunciado constitui o "lado de fora" $\mathrm{e}$ aponta os limites de um discurso.

$\mathrm{Na}$ Arqueologia do saber, Foucault destaca que o enunciado não é equivalente a um ato de fala e nem uma proposição. Se Foucault procura distinguir o enunciado de qualquer sistematização gramatical, é porque, para ele, o enunciado representa um tipo muito específico de ato discursivo, ou seja,

ele se separa dos contextos locais e dos significados triviais do dia a dia para constituir um campo mais ou menos autônomo e raro de sentidos que devem, em seguida, ser aceitos e sancionados numa rede discursiva, seguindo uma ordem (VEIGA-NETO, 2003, p. 95).

A delimitação da formação de um discurso é impugnada por Foucault por não apresentar contornos tão definidos e continuidades tão suaves quanto possa parecer à primeira vista. A perspectiva arqueológica busca uma escavação dos sentidos, uma inquietação perante as lisuras discursivas:

o que ela quer revelar é o nível singular em que a história pode dar lugar a tipos definidos de discurso que têm, eles próprios, seu tipo de historicidade e que estão relacionados com todo um conjunto de historicidade diversa (FOUCAULT, 1987, p. 186).

Torna-se vital, portanto, a composição de uma relação entre os discursos e os domínios nãodiscursivos, já que um enunciado não significa isoladamente. $\mathrm{O}$ valor de um enunciado só poderá ser apreendido (ainda que parcialmente) a partir de sua inserção em um universo de outros enunciados. 
De maneira geral, podemos afirmar que a escavação arqueológica não visa explicar e imputar sentidos ao texto, localizando uma matriz referencial para sua interpretação, mas, antes, "definir os discursos em sua especificidade; mostrar em que sentido o jogo das regras que utilizam é irredutível a qualquer outro" (FOUCAULT, [1969] 1987, p.159). Para atingir esse objetivo a arqueologia busca, portanto, uma análise das condições históricas que se entrecruzaram para que, em um determinado momento histórico, um dado enunciado tenha sido possível. A noção de Formação Discursiva (doravante FD) representa um elemento crucial para o processo arqueológico já que ela é

um conjunto de regras anônimas, históricas sempre determinadas no tempo e no espaço, que definiram em uma época dada, e para uma área social, econômica, geográfica ou linguística dada, as condições de exercício da função enunciativa (FOUCAULT, [1969] 1987, p.153-154).

O autor propõe uma análise que não se feche na matéria própria do discurso, mas que busque regularidades exteriores, ou de maneira mais assertiva, não-discursivas. Um dado discurso sempre se relaciona com outros discursos ou outros componentes alhures. Uma dada FD penetra concomitantemente em variados campos de relações, e em cada um deles, a posição que ocupa é outra, dependendo do jogo de poderes em questão. Essa característica imputa maior fluidez ao conceito de FD, visto que elas podem se modificar no decorrer do tempo ou da mudança do espaço, criando alterações no enunciado e, consequentemente, na formação de discursos e efeitos de sentido. Temos, portanto, um enunciador que, "ao mesmo tempo em que é constituído pela FD, contribui, por meio das práticas sociais e discursivas, para constituí-la, em um constante movimento de (re)configuração" (NETTO, 2008). A estrutura da FD fornece "pistas" para apreensão de seu engendramento e a partir dessas informações torna-se possível determinar o jogo de relações atuantes. Toda FD é constituída dentro de um jogo de regras e regularidades que não podem ser observadas à luz de uma metodologia descritiva-qualitativa, pois esta desconsidera o fator histórico como determinante na possibilidade de aparição dos enunciados (FERNANDES, 2012).

Entendemos, assim, que todo enunciado comporta princípios de regularidade que podem ser examinados, porém nunca esgotados em suas possibilidades de interpretação. Foucault almeja buscar regularidades entre a aparente descontinuidade dos discursos e é justamente função do trabalho arqueológico descobrir as regras que os unifica. A definição de um sistema de relações deve ser capaz de dar conta de uma FD a partir de suas escolhas estratégicas. Foucault considera as relações entre objetos, entre tipos enunciativos, entre conceitos e entre estratégias os mecanismos de passagem da dispersão dos discursos à sua regularidade. De forma geral ele afirma

No caso em que se puder descrever, entre um certo número de enunciados, semelhante sistema de dispersão, e no caso em que entre os objetos, os tipos de enunciação, os conceitos, as escolhas temáticas, se puder definir uma regularidade (uma ordem, correlações, posições e funcionamentos, transformações), diremos, por convenção, que se trata de uma formação discursiva (FOUCAULT, [1969] 1987, p. 43).

No tópico a seguir discutiremos os tipos de organização e sistemas político-econômicos que permitiram a produção dos discursos acerca do projeto EJA. A seleção desse conteúdo se deu por sua relação com discursividades produzidas pelos professores pesquisados neste trabalho. Apresentaremos, portanto, acontecimentos históricos que interpelam os discursos dos professores assim como recortes discursivos com o objetivo de melhor explorar tal ligação.

\section{Acontecimentos discursivos no Brasil República}

A educação básica para jovens e adultos no Brasil República marcou lenta e tardiamente seu lugar na história dos processos democráticos do país (VÓVIO, 2007). Em 1889, na ocasião da Proclamação da República, o Brasil reconheceu a necessidade do acesso à educação para sua população integralmente e não somente para as elites. Nessa época, as taxas de analfabetismo eram preocupantes e chegavam a $75 \%$ da população; porém, somente em 1934 foi instituída a obrigatoriedade e a gratuidade do ensino básico para todos. Em 1947, o governo lançou a primeira Campanha Nacional de Educação de Adultos. De acordo com Haddad E Di Pierro (2000, p. 110), "foi somente ao final da década de 1940 que a educação de adultos veio a se firmar como um problema de política nacional". O projeto recebeu atenção diferenciada, verbas e planejamento específicos. Com base nos dados do gráfico abaixo, podemos perceber que os índices de analfabetismo no país declinaram em mais de $50 \%$ do início da década de 40 até o ano de 2010. Neste período, os centros urbanos se organizaram a partir da crise econômica cafeeira e da Revolução de 
1930.

Gráfico 1: Censo demográfico entre 1940 e 2010

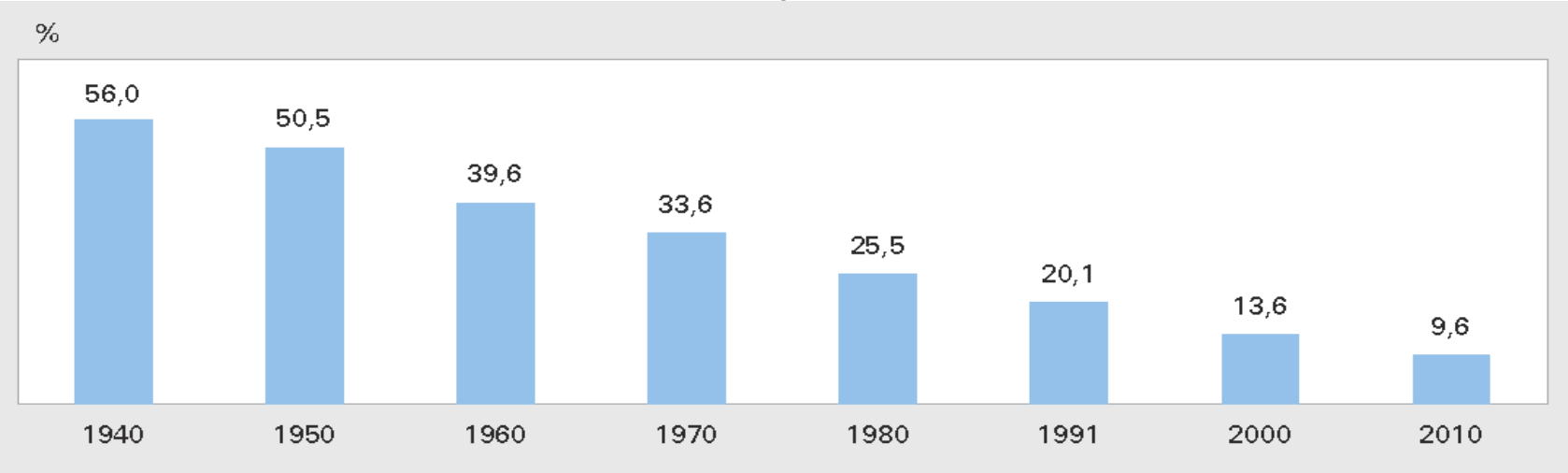

Fonte: IBGE. Censo demográfico $2010^{3}$.

Apesar da notável alteração das estatísticas, o foco dos governantes no direito à educação básica ainda não havia saído efetivamente do papel. As campanhas políticas sustentavam um dizer que não se refletia na realidade da população. Os políticos buscavam acalmar pressões populares e 'capacitar' mão de obra para a indústria. De acordo com Ferraro (2002) e Vóvio (2007), a modificação nos números ocorreu devido a alterações na própria estrutura do país, advindos da então recente urbanização e seus desdobramentos (o crescimento e o movimento populacional e a demanda de maior mão de obra na indústria).

A educação precisava se tornar mais acessível e os índices de analfabetismo deveriam diminuir para que o Brasil alçasse o posto de país bem estruturado e economicamente forte. A educação serviria de trampolim para ascensão, como fica notório no excerto do II Congresso Nacional de Educação de Adultos em 1958,

(...) $\mathrm{O}$ elemento humano convenientemente preparado que necessita nossa expansão industrial, comercial e agrícola tem sido e continua a ser um dos pontos fracos da mobilização de força e recursos para o desenvolvimento. Essa expansão vem sendo tão rápida, que não podemos esperar a sua formação regular de ensino; é preciso uma ação rápida, intensiva e ampla e de resultados práticos e imediatos, a fim de atendermos às necessidade de nosso crescimento.

A busca pela acessibilidade da educação e transformação estrutural era tanto interna quanto externa. A própria Unesco já havia feito apelos ao país para que as campanhas se efetivassem como movimentos consolidados na queda dos números relativos ao analfabetismo. Muitas campanhas (Campanha Nacional de Educação de Adolescentes e Adultos [1947- 1958]; Mobilização Nacional de Erradicação do Analfabetismo [1947- 1950]; Movimento de Educação e Base [1961]) foram criadas e implementadas em diversas regiões do país, tornando-se visível o interesse pelo fim do analfabetismo. A questão do analfabetismo

foi tratada como um mal que assolava a sociedade e que precisava ser erradicado; era preciso diminuir a "ignorância" e formar um "coletivo eleitoral" que viesse a responder aos interesses da elite política (SOUZA, 2007, p.83).

Gostaríamos de nos ater aqui ao uso/escolha da unidade lexical "erradicar", palavra constantemente aludida nas campanhas nacionais. De acordo com o dicionário, a formação nominal oriunda do latim erradicare, significa arrancar, desarraigar. Os efeitos de sentido suscitados pela palavra nos remetem a algo que devesse ser banido, exterminado. $\mathrm{O}$ vocábulo é comum na área da saúde em campanhas de combate às enfermidades. De acordo com Dias (2012), "uma unidade sintática é articulada, isto é constituída articulatoriamente, na medida em que os seus constituintes já participaram de outras unidades em outros domínios de enunciação da língua". A utilização da palavra nestes campos do saber diferentes evidencia a produção de um discurso higienista que propaga a ideia de contaminação, sujeira e acaba imputando ao analfabeto o lugar de doente, alguém que precisa ser curado. Essa memória discursiva cria um imaginário social que não cessa de reverberar nos discursos científicos, políticos e dos próprios profissionais que trabalham com o projeto, como foi observado neste 
trabalho. Analisando os fatos discursivos, nós percebemos que os alunos do projeto são percebidos por alguns professores como alunos "cognitivamente comprometidos" ou "anormais". Vejamos alguns recortes discursivos dos sujeitos participantes da nossa pesquisa que corroboram essa visão (grifos nossos):

(1) "Vocês não precisam entender o que está escrito. Só encontrar o verbo. Você precisa saber o verbo to be, o simple present, só isso." E é impressionante como eles fazem. Tão fazendo exercício pra mim de forma incrivel. (Valéria)

(2) (...) é pq eu trato o aluno da EJA de uma forma bem tipo assim sem nenhuma discriminação (...) eu sei que o processo cognitivo tá comprometido, tem que trabalhar muita coisa eu entendo isso. (Valéria)

(3) A turma que eu tenho eles têm uma limitação enorme. Nem dicionário eles sabiam consultar direito. (Lúcia)

(4) A valorização a gente dá a eles colocando eles como alunos normais e não de projeto. (Lúcia)

$\mathrm{Na}$ enunciação, predica-se o que "se configura como pertinente a uma demanda exterior que afeta o sujeito, e assim ele entra no campo do dizer sob o efeito da constituição da diferença." (DIAS, 2012, p. 22). Desse modo, podemos perceber que no enunciado 1 acima, através dos adjetivos intensificadores impressionante e incrivel, a professora se mostra espantada ao ver seus alunos realizarem exercícios que ela própria qualifica como simples. A presença dos advérbios não e só também vem conferir ideia de simplificação. A professora emprega o substantivo discriminação logo antes da preposição sem e essa construção faz ecoar o discurso da exclusão através do resgate de um nãodito implícito. Os outros dizeres dos professores também reforçam esse discurso quando colocam o aluno como um sujeito incapaz de realizar funções básicas como usar um dicionário ou os denominando alunos anormais.

\section{A ditadura militar e a EJA}

As campanhas de alfabetização estabelecidas a partir da década de quarenta transcorreram sem grandes alterações até a década de sessenta. Em 1964, o Brasil sofre o golpe militar e os planos nacionais de alfabetização são interrompidos. A escolarização de jovens e adultos ganha contornos de ensino supletivo e o Movimento Brasileiro de Alfabetização, que ficou conhecida pela sigla Mobral é instituído em 1967. Foi transmitida ao educador a imagem de um aluno tímido e inseguro e cabia ao professor a modificação desse quadro. Nos documentos oficiais, o objetivo maior era o amplo atendimento à população e acreditava-se que o progresso de cada um estava condicionado a fatores de ordem pessoal e ao esforço empreendido pelos sujeitos em aproveitar as oportunidades educacionais oferecidas pelo Estado (HADDAD; DI PIERRO, 2006). O governo disponibilizou uma grande soma de recursos para responder às demandas externas relacionadas a projetos econômicos (visto que o analfabetismo era visto como responsável por atravancar o crescimento econômico da população) e estipulou o fim do analfabetismo em dez anos.

A base metodológica e o material do Mobral centravam-se na funcionalidade. $O$ termo, na realidade, objetivava desenvolver o aluno e preparálo para desempenhar alguma função na sociedade. Tanto no material quanto em sala de aula, qualquer posicionamento crítico ou questionador sobre a realidade era (ou deveria ser) coibido. O material didático era também preparado para adaptar o aluno às novas configurações socioeconômicas e à manutenção do status quo (BELLO, 1993). Assim o Mobral

concebe a educação como investimento, como preparação de mão-de-obra para o desenvolvimento inquestionável. A ênfase na decodificação da palavra, na aprendizagem das técnicas de ler e escrever, facilita o desenvolvimento de habilidades que permitem a apreensão de informações que fazem o alfabetizando entrar no grupo de que participam do desenvolvimento (JANNUZZI, 1987, p. 65).

O Mobral foi um programa extremamente centralizador e, devido aos maciços investimentos, se disseminou por todo o país; porém não conseguiu acabar com o analfabetismo naquela década. O programa acabou sendo extinto em 1985 na transição para a democracia e foi substituído pela criação da Fundação Educar, que passou a financiar iniciativas do governo, entidades civis e empresas conveniadas à essa fundação (VÓVIO, 2007).

\section{Acontecimentos discursivos a partir da década de 90}

Os discursos formados pela configuração político-econômica da década de 1990, assim como os outros discursos circulantes já apresentados, formaram a base para a construção, 
a mudança e/ou o restabelecimento de maneiras de entendimento do tempo presente. Por volta de 1990, o mundo estava sob influência das práticas neoliberais ${ }^{4}$ e, assim, aconteceram vários encontros internacionais para o estabelecimento de uma nova ordem educacional. Um desses encontros foi a Conferência de Educação, realizada na Tailândia em 1990. Nessa reunião, cujo tema era "Educação para todos", a melhoria e a expansão da educação para jovens e adultos foi enfatizada e metas foram estipuladas. Em 1993, noutra conferência em Nova Delhi, os números de analfabetismo do Brasil foram (re)analisados e o país foi considerado um país em desenvolvimento com índices a serem superados. Para Soares (2001), os anos finais da década de 90 trouxeram um intenso movimento na Educação de Jovens e Adultos no Brasil devido ao acontecimento da V Confitea, com a participação de representantes de governos e organizações não-governamentais e da sociedade civil.

Diversos projetos foram empreendidos sob a tutela dos pressupostos neoliberais, a exemplo o programa 'Amigos da escola' e o documento elaborado pelo Instituto Herbeth Levy — "Ensino Fundamental \& Competitividade Empresarial: uma proposta para a ação do governo". A própria LDB9394/96 (nova Lei de Diretrizes e Bases - LDB 9.394, sancionada em 20 de dezembro de 1996, pelo Presidente Fernando Henrique Cardoso) fortalece a ideia do engajamento social na promoção de políticas públicas enfraquecendo o lugar do Estado como centralizador.

Até então, procuramos ressaltar como o acesso aos processos educacionais esteve estreitamente relacionado, principalmente, aos fatores socioeconômicos. Assim, a educação acabou por exercer uma função segregadora ao distinguir, no cerne de seu próprio processo educativo, sujeitos inseridos em práticas valorizadas socialmente e sujeitos que não possuíam condições de frequentá-la. A escola era e ainda é veiculada nos documentos e discursos oficiais como uma instituição capaz de alterar sistemas, preencher lacunas e assim produzir mudanças em toda esfera política, econômica e social de um país. As campanhas propostas tinham (e ainda possuem) como metas programas de educação para as "massas". Estas campanhas possuíam caráter imediatista, num esforço e investimento muito mais quantitativo do que qualitativo. Procuraremos agora apresentar um olhar mais qualitativo para a EJA a partir dos dizeres que depreendemos de nossos cinco professores de língua inglesa atuantes nesses programas.

\section{A constituição do corpus}

Para construção de nossa investigação, optamos pela pesquisa de cunho qualitativo porque, como estudiosos do campo da linguagem, entendemos que essa escolha permite maior possibilidade de interpretação/descrição dos fatos linguísticos, já que "o dizer é o próprio fato" (ORLANDI, 1996, p. 20). Elegemos também as entrevistas semi-estruturadas orais realizadas com cinco professores(as) de língua inglesa. A escolha por esse tipo específico de formação do corpus se deu, principalmente, porque acreditamos que a fala pode trazer "momentos privilegiados da equivocidade da língua, que são manifestados na forma de lapsos, silêncios, interrupções, rupturas do pensamento, bem como nos acréscimos e, até mesmo, no riso" (ANDRADE, 2008, p.90). Ao cometer esses tropeços, o sujeito deixa rastros que não são possíveis de serem desmanchados e estão marcados na linha do dizer. Antes, porém, cabe explicitar de que modo tomaremos os dizeres para análise, senão pela via da representação.

\section{As representações}

De acordo com o dicionário ${ }^{5}$, representar significa 'ser a imagem ou a reprodução de algo'. Dessa forma, e, em termos generalistas, temos então, a oposição entre esse 'algo' pleno de essencialidade e imanência e, do outro, um suporte referencial. Essa noção parece suportar a concepção de uma relação contígua entre duas partes (esse 'algo' e sua apropriação humana). Questionamo-nos então sobre o que constituiria a palavra e o que constituiria a coisa, já que consideramos que todo o trabalho de mediação é, em si, um trabalho de interpretação, em suma, uma tentativa de (in)corporação do outro, presa na engrenagem da linguagem.

De acordo com o escritor e psicanalista Luis Alfredo Garcia Roza em sua leitura sobre o esquema freudiano (GARCIA-ROZA, 1991), a apreensão da realidade pelo sujeito não se dá a partir de um encadeamento lógico e linear e nem como um projeto idêntico dessa realidade. Assim, a representação psíquica, em Freud, desloca a acepção de representação como simples moção mecânica, para a consideração de um processo de consideração dos aspectos psíquicos. Os processos psíquicos seriam vetores que produziriam jogos associativos apreendidos pelo sujeito. Nesse intricado sistema 
associativo, o que temos não é o objeto a priori, mas associações que se dispõem em torno desse objeto (vale lembrar que, aqui, tomamos essas associações como provenientes do registro imaginário ${ }^{6}$ do sujeito). Dessa forma, os processos de associação não podem ser desvinculados da noção de representação, sendo esta sempre elaborada enquanto sistema complexo que comporta o arranjo de grande variedade de elementos em sua estrutura. $O$ processo de associação se dá à revelia do sujeito amparado nas identificações ${ }^{7}$ que este estabelece com o mundo. Sendo assim, podemos concluir que as representações são, também, matéria do inconsciente $\mathrm{e}$, por isso, singulares. No tocante ao funcionamento psíquico das representações, elas produzem significação quando se relacionam entre si. De acordo com Garcia-Roza (1991),

A significação não está na coisa, também não está em cada imagem (visual, tátil, acústica, etc.) como se cada uma delas representasse um elemento da coisa; ela resultaria da associação destes vários registros pelos quais se dá a representação. [...] Tudo se passa, portanto, no registro da representação e da associação entre representações" (GARCIA-ROZA, 1991, p.4849).

De maneira sucinta, percebemos então que as representações comportam elementos de ordem inconsciente que apontam para o registro da singularidade ao mesmo tempo em que compartilham elementos de ordem social. Nas palavras de Neves (2012),

(...) as representações se referem às imagens de si, do outro e do referente e são de ordem inconsciente. Elas são tanto da ordem do coletivo, ideologicamente carregadas e mais ou menos estereotipadas, quanto da ordem da singularidade (capacidade de suportar a angústia de ser diferente) dos envolvidos, pois dizem algo de seu desejo e da responsabilidade por suas escolhas pessoais (NEVES, 2012, p. 77).

Nesse sentido, concordamos com Grigoletto (2003) ao afirmar que as representações deixam entrever o que o sujeito toma pra si do mundo e, por conseguinte, suas identificações. A noção de representação aqui desenvolvida não é insensível às mudanças, mas, como se relaciona com os processos sócio-históricos e inconscientes, está sempre em movimento (NEVES, 2006).

Partindo da premissa que as representações são constituídas a partir de um imaginário social e que também são da ordem da singularidade, apostamos que elas podem revelar as formações discursivas nas quais os professores de EJA se inscrevem (MASCIA, 2011) e nos auxiliar a compreender quais são as posições que o professor assume em seus dizeres.

\section{Desvelando as tramas discursivas}

Esta seção objetiva desvelar as relações que os sujeitos estabelecem com o trabalho com a língua estrangeira na EJA. O que nos contam esses professores sobre suas identificações com o projeto EJA? Quais são as representações sobre o seu trabalho na EJA?

Ao serem questionados sobre a motivação inicial por esse trabalho, esses professores expressaram diferentes justificativas. É importante ressaltar que, dentre os seis professores entrevistados, três optaram pelo trabalho com a Educação de Jovens e Adultos, enquanto os outros três foram designados. Cabe-nos analisar, portanto, a especificidade de cada ocorrência. Vejamos, abaixo, algumas sequências discursivas:

(24) Não na realidade eu não escolhi né não foi uma escolha trabalhar com EJA né eu fui porque eram as aulas como eu sou a segunda professora eram as aulas que sobraram peguei mas é uma turma assim é a que eu mais gosto de trabalhar é com EJA. (Lúcia)

(25) Eh... deixa eu te falar eu iniciei com o ensino fundamental né ai eu já trabalhava no que antes era quinta até oitava né agora é sexta até oitava eu já estava aqui nessa escola e aqui nessa escola eu sempre estou em todas as turmas sabe? então surgiu oportunidade eh... de trabalhar com os meninos da tarde que é o sexto ano e com os meninos da noite que é o projeto EJA e aí eu fui (Maria)

Neste primeiro recorte discursivo, Lúcia deixa irromper, pela (re)ocorrência do advérbio de negação não e pela ênfase no caráter eventual da situação (aulas que sobraram), sua primeira reação ao trabalho com a EJA. A negação indica que o trabalho com jovens e adultos não partiu de uma moção de aspiração prévia, mas de uma casualidade. Ao fazer remissão ao verbo sobrar, ela sinaliza para $\mathrm{o}$ aspecto residual, indesejado das aulas de EJA em sua escola.

$\mathrm{O}$ emprego da expressão na realidade nos fez atentar para algo que estava submerso, mas que Lúcia decidiu tornar visível naquele momento. Em 
um ato confessional, a professora admite que não lhe foi oferecida a possibilidade da escolha, imprimido assim a leitura que, caso pudesse (es) colher ${ }^{8}$, tomaria outro caminho, mas pegou as tais aulas. Parece pertinente interrogar, neste momento, sobre o mecanismo pelo qual o sujeito se sente impelido a descortinar algo. O dispositivo confessional, tal como desenvolvido por Foucault (1987), é um ritual de lugares marcados onde cada sujeito ocupa uma determinada posição enunciativa. De um lado, o inquisidor e do outro, o suspeito. Ambas (con)formações discursivas encenam um jogo que tanto assevera a estrutura de poder preexistente, quanto alivia o faltoso. Temos, nesse recorte, marcas que se apressam em sobrevir, possivelmente, no afã de atender às expectativas imaginárias construídas sobre o pesquisador e sua pesquisa. Lúcia se esmera em proferir alguma palavra de conotação positiva para nos relatar sobre seu trabalho com a EJA (mais gosto). Nesta busca, ela tropeça na conjunção adversativa mas (mas é uma turma assim é a que eu mais gosto de trabalhar é com EJA) contradizendo o que acabara de enunciar e se apossando do vocábulo assim (aqui com a função de marcador discursivo orientador) de modo a registrar incerteza frente à caracterização do trabalho em questão. $\mathrm{O}$ advérbio assim pode funcionar no discurso como uma marca capaz de prover tempo para que seu enunciador reorganize sua fala. Arrematando seu encadeamento lógico em seguida, a professora concede ao grupo um alto valor afetivo.

$\mathrm{Na}$ fala de Maria, temos um processo semelhante no que tange seu inicial (des)interesse pelo trabalho com o projeto EJA e suas construções discursivas atuais. A professora também não o es(colheu), mas aceitou a oportunidade. As palavras usadas por ela (eu já estava aqui nessa escola e aqui, e aí eu fui) nos remetem à ideia de casualidade. Não percebemos em seus dizeres nenhum interesse pela EJA em si, somente uma oportunidade que se fez presente. As marcações de tempo e espaço em seu dizer (aqui nessa escola, sempre estou) nos indicam que talvez a relação de Maria com a escola tenha sido fundamental na sua decisão.

Muitos professores desconhecem o trabalho com a EJA, já que por ser um ensino considerado inferior, aponta Arroyo, é pouco discutido em cursos de licenciatura (ARROYO, 2001). Se a EJA é uma entre outras modalidades de ensino, por quê o silêncio? Esse silenciamento preponderante nas instituições educacionais nos leva a perceber que existe algo da memória discursiva sobre a EJA que incide até mesmo nas tomadas de decisão das diretrizes dos cursos de licenciatura. Se o professor não tem chance de falar sobre a EJA e produzir sentidos que possam desafiar outros pré-construídos relativos a esse trabalho, muito possivelmente seus dizeres sobre a EJA serão constituídos a partir de uma série de repetição de já-ditos sobre o tema de forma mnemônica (ORLANDI, 1996).

Analisemos agora os dizeres da professora Ana Maria sobre os motivos que a incentivaram a trabalhar com a EJA:

(26) Olha eu quis o trabalho de jovens e adultos primeiramente eu já estava dentro da escola eu trabalhava lá com a educação infantil dava aula de português, geografia e história e aí eu fiquei sabendo que tinha o EJA à noite como eu queria fazer inglês eu falei nossa é agora eu vou mudar minha habilitação vou trancar a faculdade vou estudar o inglês aí eu tranquei a faculdade não tinha inglês nenhum aí tranquei a faculdade fiz um semestre tranquei a faculdade e já corri lá na escola e fiz a minha inscrição pra participar do processo seletivo aí eu passei entendeu? mas assim eu acho que o trabalho é maravilhoso assim é uma experiência única porque primeiro porque você tem contato com pessoas maravilhosas que são os alunos né que são mais velhos voltam a questão de estudar eles querem nossa é lindo o trabalho mas porque eu queria ter essa experiência sem essa pressão de escola de curso de inglês ou qualquer ou escola mesmo regular eu queria poder ser livre quando eu fosse trabalhar e como eu não tinha um inglês ainda então eu podia e... fazer de forma com que de acordo com meu nível e que era superior ao nível que eu deveria ensinar. Então eu tava tranquila. (Ana Maria)

Ao ser indagada pelos motivos que a levaram a ocupar a posição de professora de EJA, Ana Maria resgata de sua memória uma narrativa repleta de acontecimentos. Ela encadeia uma série de ações na sua narrativa (tranca a faculdade, muda a habilitação, estuda, participa do processo seletivo) para conseguir trabalhar como professora de EJA. A psicanalista Maria Rita Khel (2001, p; 57-8) aponta que ao enunciar sobre si, o sujeito se coloca em posição de destaque e constrói uma narrativa sequencial e aparentemente sem furos, que envolve e seduz o espectador. A (cri)ação confere efeitos de unicidade e se constitui como um "imperativo de tudo dizer ao Outro, a algum Outro suposto capaz de colocar ordem na fragmentação e na dispersão das identificações que compõem o frágil revestimento imaginário do eu na modernidade" (2001, p.62). 
Através da estrutura "é agora eu vou mudar..." podemos deduzir que, ainda que uma escolha, a decisão pelo trabalho com EJA se apresentou como uma oportuna circunstância. A aparição desse cenário parece ter impulsionado Ana Maria a se livrar de uma configuração (decerto) indesejada e partir rumo ao enlace de seu desejo. A professora trancou a faculdade, estudou inglês, se inscreveu e passou em um processo seletivo. A abundância de verbos de movimento em seus dizeres de apontam para o fato de que sua motivação não passava somente pela ordem da palavra, mas do investimento subjetivo para atingir um objetivo. A falta, que mobiliza o sujeito, foi o que fez com que ela buscasse na EJA seu espaço.

Através da observação do dito em sua relação com o não-dito, podemos resgatar que, nas palavras de Ana Maria, o trabalho com a EJA exigiria dela menos esforço por ser um trabalho sem pressão, livre, tranquilo. Se temos que "ao longo do dizer, há toda uma margem de não-ditos que também significam" (ORLANDI, 1996, p. 82), a relação de oposição produzida por essa materialidade sustenta que entre a escola regular e a EJA, o cursinho de inglês e a EJA, qualquer escola ou a EJA, a EJA se torna o lugar do não-regular, da despreocupação.

Ao explorarmos a materialidade linguística, deparamos-nos com as predicações que circunscrevem a posição de Ana Maria. Esses dizeres nos levam a pensar, inicialmente, que ao empreender tanto esforço na pretensão de se tornar professora de EJA, ela talvez esteja identificada com esse lugar. Convém pontuar, entretanto, que diferentemente dos outros entrevistados, a professora em questão demonstra, discursivamente, um gosto pelo trabalho com a EJA, justamente devido à sua identificação aos dizeres que consideram essa modalidade de ensino um espaço menor, inferior. Voltemo-nos aos vocábulos. Livre, por exemplo, de acordo com o dicionário, é um adjetivo de dois gêneros, que indica aquele que obteve livramento, o absolvido. Outra palavra que nos chama a atenção é pressão, que suscita a ideia de tensão. Estas duas concepções (absolvição e tensão) desvelam o conflito engendrado e amplamente estudado por Freud em Mal-estar na civilização (1930), que se caracteriza pela perene disputa entre o gozo da satisfação pessoal ou o conforto do reconhecimento do outro, visto que existe um antagonismo intransponível entre as exigências da pulsão e as da civilização. Assim, para o bem da sociedade, o indivíduo é sacrificado de modo que, para que a civilização possa se desenvolver, o homem tem que pagar o preço da renúncia da satisfação pulsional. A castração se coloca e Ana Maria parece tentar retirar satisfação de seu lugar de professora ali, sem ter que prestar contas às demandas sociais, em cujo protocolo se supõe que o trabalho com a EJA não seja importante.

Em nossos gestos de interpretação, entendemos que Ana Maria escolheu trabalhar com a EJA justamente pelo que ela não lhe oferece. A EJA não lhe confere risco ou pressão, sendo realmente uma experiência única a seu ver. O projeto EJA ou os alunos não foram somente a causa do desejo, mas a sua possibilidade de realização. É somente nessa modalidade que ela se autoriza a lecionar um conteúdo que diz não saber.Ao escolher o trabalho com a EJA, justamente pelo que ele não lhe oferece, a professora, ainda que de maneira inconsciente, desvia o foco sobre si mesma e sobre suas limitações de língua.

Nesse momento, nos implicamos com o que verdadeiramente tocou a professora e propiciou tantos deslocamentos ${ }^{9}$ subjetivos (NEVES, 2008). Ela já era professora, portanto não foi por esse lugar que ela despendeu tamanha energia. Ao retomar a materialidade linguística, percebemos que no seguinte trecho "é lindo o trabalho mas" Ana Maria nos permite flagrar que não foi o trabalho com o projeto, ou a posição de ser professora o que lhe mobilizou. A conjunção adversativa mas sustenta a noção deque algo novo e importante estaria por vir: ser professora de língua inglesa. Essa relação com a língua pode tanto ter sido encetada por um processo identificatório com a língua ou foi movida pelo status que a língua desfruta no mundo (já que ela já era professora de português, história e geografia). Dentro desta leitura, a língua pode ocupar o papel de bem simbólico $^{10}$, algo que lhe diferencia e lhe posiciona na sociedade.

Para Ana Maria, ser professora não se traduz em conhecer a disciplina ensinada, mas na ocupação (ainda que parcial) desse lugar instituído socialmente (como eu não tinha um inglês ainda então eu podia e... fazer de forma com que de acordo com meu nível e que era superior ao nível que eu deveria ensinar. Então eu tava tranquila.). Percebemos que a memória discursiva sobre EJA é mobilizada e fator de decisão, mas não notamos em seus dizeres nenhum processo de identificação com o projeto. Este funcionaria apenas como um espaço, sem grandes exigências, onde se pode exercer livremente a função de "professor".

É preciso mencionar ainda que, apesar do papel fundamental da memória no processo de constituição do sujeito, ele é único e por isso irá se 
posicionar de maneira ímpar perante os acontecimentos ao seu redor. O processo de inscrição do sujeito na linguagem o torna assujeitado ao seu sistema e aos seus furos, mas é somente através de processos identificatórios que ele se filia a um determinado recorte de significação e assume determinadas (mas variáveis) posições no discurso. Dentro de nosso corpus, percebemos que o enunciado de Antônia (abaixo) se distancia dos discursos que consideram a EJA um espaço do residual, excluído e marginal e assim, Antônia não manifesta em seus enunciados a (con)formação desses sentidos. A identificação desses dizeres que rompem com a memória discursiva discutida acima, nos sugere uma ruptura com o discurso mais conformado ao ensino marginal da EJA. Observemos o que Antônia nos diz sobre seu trabalho na EJA:

(28) trabalhar com EJA... eu não sei bem ...o que que quer dizer porque eu acho que quando você é profissional você tem que trabalhar com o grupo que tá na sua frente. Eu não sei ...eu não sei o que isso quer na verdade dizerassim eu sou uma professora eu sou uma professora de inglês e estou trabalhando com um grupo de EJA e tô fazendo o melhor que eu sei agora só isso. (Antônia)

Entendemos que, para uma maior percepção das condições de produção desses dizeres, é relevante comentarmos brevemente algo sobre o percurso profissional da professora. Antônia possui o título de mestre e é uma professora que trabalhou há mais de uma década em uma universidade particular em Belo Horizonte. Na época da entrevista, a professora iniciava seu trabalho na rede pública federal de ensino e dessa forma, no semestre em que a entrevistamos, ela estava tendo a sua primeira experiência com a EJA.

Observamos em seus dizeres oscilações entre primeira e segunda pessoa (eu não sei bem o que que quer dizer porque eu acho que quando você é profissional você tem que trabalhar...), que podem indicar que a pergunta a tenha pego desprevenida. Por diversas vezes, temos a construção negativa não sei, seguida por momentos de pausa (eu não sei bem; Eu não sei ...eu não sei o que isso quer na verdade dizer) indicando o seu desconhecimento das especificidades da modalidade em questão. Percebemos também que esses dizeres não trazem marcas que fazem ecoar enunciados que percebem a EJA como algo residual e menor (o que não quer dizer que outros discursos não a constituam). Talvez pelo fato de lidar de modo mais flexível com o não- saber que o trabalho com EJA representa para sua prática pedagógica, ela se explica buscando fazer comentários mais abrangentes sobre a condição do profissional da contemporaneidade. Ela alude à questão do profissionalismo e ao final de seu enunciado anuncia: tô fazendo o melhor que eu sei agoral só isso (grifos nossos). O emprego do advérbio só nos remete à ideia de que ela já sabe o que é necessário fazer para conseguir desenvolver um bom trabalho, e que a EJA é mais uma entre tantas outras situações de ensino. O uso de deônticos (quando você é profissional você tem que trabalhar com o grupo que tá na sua frente) (grifo nosso) nos indica que esse dizer é atravessado pelo imaginário social da competência, da produtividade, em todas as situações de ensino, independente de qual seja.

De fato, a questão da alta produtividade é uma máxima em tempos de economia capitalista. Conforme discutimos no segundo capítulo, a educação em tempos neoliberais requer um profissional que opere de acordo com a lógica de um mercado voltado para seus fluxos, em carência permanente de mercadorias para consumir (DUFOUR, 2005). Então, é esperado que o professor, assim como o operário da fábrica, seja ágil e adaptável para a produção de resultados benéficos para a empresa (lembrando que Antônia tem larga experiência em empresas educacionais de capital privado). Sobre essa discussão, Moreira e Kramer (2007) comentam que

Na educação, o comportamento flexível é tanto demandado dos professores quando difundido, como habilidade a ser adquirida, aos estudantes, futuros trabalhadores. Estimula-se o professor, por diferentes meios, a adaptar-se a circunstâncias variáveis, a produzir em situações mutáveis, a substituir procedimentos costumeiros (às vezes repetitivos, às vezes bem-sucedidos) por "novas" e sempre "fecundas" formas de promover o trabalho docente. (...) Subjacente a todos esses princípios e comportamentos, que visam reinventar a escola, tendo por norte padrões globalmente definidos, está a preocupação com o sucesso, com a eficiência, com a eficácia, com a produtividade, com a competitividade, com a qualidade na educação (entendida segundo os parâmetros vigentes) (MOREIRA; KRAMER, p. 1041, 2007).

Percebemos em Antônia, portanto, a busca de se afirmar como uma boa profissional, diante da imagem que ela projeta de si perante o outro. Heterogeneamente constituído, seu dizer nos mostra que sempre existe um outro que me vê e me diz que 
eu tenho que atender à sua demanda. Nesse caso, sua representação de uma professora é a de alguém que detém a responsabilidade de promover essa imagem de um profissional habilitado, preparado para o mercado de trabalho. Para o psicanalista Jacques Lacan "o outro é aquele que me vê, e é isso que, por si só, faz travar-se a luta (...)" (LACAN, 2005, p. 33). Essa luta da qual Lacan fala é a luta que travamos conosco para atingir o outro e suas expectativas. $\mathrm{O}$ outro que não tem corpo definido, pode ser aqui representado pelo colega de profissão, a instituição ou, nesse caso, o pesquisador. O discurso neoliberal, por trabalhar em prol do desenvolvimento ininterrupto, é um discurso que tem pouca tolerância à não-conformação com os parâmetros de eficiência e eficácia estabelecidos pelo mercado da educação. Em nosso gesto de interpretação, entendemos que Antônia assume a posição de um sujeito que atribui sentidos a esse discurso da adaptação e da flexibilidade profissional.

\section{Considerações finais}

Embora acreditássemos que o fato do professor ensinar a língua inglesa e não outra disciplina imprimisse efeitos de sentido que pudessem diferenciar suas posições de outros professores, observamos que somente uma das participantes destacou esses efeitos, atribuindo o seu trabalho na EJA como motivador de seu desejo próprio de aprender e aprimorar essa língua. Os demais não necessariamente especificaram o ensino da língua como diferente do ensino de outras disciplinas. Entretanto, através do exercício analítico, observamos que a memória discursiva exerce um papel crucial nas decisões desses professores ao escolherem ser professores de EJA, em movimentos tanto de aproximação quanto de afastamento. Alguns professores assumem o trabalho com a EJA em um caráter de eventualidade, atribuindo ao projeto um sentido residual, indesejado. Outros a buscam justamente por causa dessa conformação de sentidos, o que faz com que se sintam menos pressionados e mais à vontade com seu trabalho (seja nos acertos ou nos erros cometidos em sala de aula).

Entre os recortes escolhidos para a nossa análise, gostaríamos de destacar os enunciados de Antônia, por se distinguirem dos demais. A professora Antônia não parece perceber a EJA como um espaço menor ou indesejado e dessa forma, pode estabelecer uma relação pedagógica que vai se dar nos encontros/confrontos inesperados na sala de aula.

De forma geral, o conjunto de representações nos possibilitou discutir um pouco sobre $\mathrm{o}$ aspecto menor - e, muitas vezes, indesejado - do trabalho com a EJA. Conforme exposto na primeira seção, o trabalho com a educação de jovens e adultos é comumente associado a palavras como menor, menos importante, periférico, preconceito. Observamos essas marcações em incontáveis enunciados, e, portanto, tais regularidades nos levaram a considerar essas regularidades uma Formação Discursiva e nomeá-la FD do Conformismo. O significante conformismo não adquire em nosso trabalho um significado pejorativo de resignação ou passividade, mas como reverberação de sentidos conformados pela história e materializados na superfície linguística seja nos documentos (que não analisamos aqui, mas examinamos em outro trabalho ${ }^{11}$ ), seja nos dizeres dos professores pesquisados. A (con)formação dessas imagens sobre a EJA funcionou como uma matriz de sentidos, que ora os aproximou desse trabalho, ora os afastou. Observamos, porém, que houve um corte nesses sentidos (pre)vistos e que, em diversos dizeres, não foram utilizados significantes que resgatassem essa memória negativamente constituída sobre a EJA.Desse modo, consideramos tais dizeres como sendo constituidores de outra Formação Discursiva, que nomeamos de FD da Ruptura. Ou seja, a ruptura com o que está (con)formado.

Conforme discutimos, as discursividades engendram o processo de subjetivação do sujeito, e dessa forma o mesmo não está destinado a apenas reproduzi-las, mas a perceber que aí existe sempre um resto, uma hiância que resiste em ser significada, conforme nos indica a psicanálise. É nesse lugar que percebemos a possibilidade da (re)invenção do sujeito. A professora Antônia nos lembra da possibilidade da descoberta perante $\mathrm{o}$ aluno, apontando assim para uma relação que se construirá com base na noção de diferença como processo estrutural a ser desvendado incessantemente na relação entre professor e aluno.

Finalmente, esperamos que esse trabalho possa dar maior visibilidade e profundidade às discussões sobre o tema da EJA e suas implicações dentro da LA, e assim, contribuir para as discussões sobre a formação de professores.

\section{Notas}

1 Artigo referente à dissertação de mestrado: LEITE, 
N. C. Entre o conformismo e a ruptura: posicionamentos discursivos de professores de língua estrangeira em educação de jovens $e$ adultos. 127 f. Dissertação (Mestrado em Linguística Aplicada). Universidade Federal de Minas Gerais, Belo Horizonte, 2013.

2 A noção de arquivo adotada neste trabalho referese ao "conjunto dos discursos efetivamente pronunciados" (FOUCAULT, 1987, p.772)

3 http://www.ibge.gov.br/home/presidencia/noticias /imprensa/ppts/0000000847310412201231572748 3985.pdf. Consultado em 30/06/2016.

4 Numa perspectiva Foucaultiana, é importante dizer que tanto o liberalismo quanto o neoliberalismo se constituem como práticas, como uma maneira se fazer política, que se orientam e regulam por princípios e métodos de uma racionalização de governo. (SANTOS, 2010). De maneira geral, podemos afirmar que é um governo de maximização da liberdade individual, descentralização administrativa e política, estimulo à autonomia individual e instituições de parcerias entre o setor privado e público.

$5 \mathrm{O}$ dicionário consultado para este trabalho foi o dicionário Houaiss da Língua Portuguesa, versão online.

6 O imaginário e o simbólico fazem parte de uma tripartição estrutural fundamentada por Jacques Lacan onde o simbólico é "a dimensão da linguagem que precede e faz o sujeito" (NEVES, 2002, p. 90) e o imaginário "designa uma relação dual com a imagem do semelhante". Lacan, a partir de 1953, o define, como "o lugar do eu por excelência, com seus fenômenos de ilusão, captação e engodo" (ROUDINESCO; PLON, 1998, p.385).

7 "Termo empregado em psicanálise para designar o processo central pelo qual o sujeito se constitui e se transforma, assimilando ou se apropriando, em momentos-chave de sua evolução, dos aspectos, atributos ou traços dos seres humanos que o cercam" (ROUDINESCO; PLON, 1998, p. 377).

8 Procuro estabelecer aqui um jogo entre a palavra colher e o ato de escolha. O verbo colher transmite a ideia de algo que foi planejado, cuidado, esperado, assim como pressupõe o ato da escolha. Etimologicamente, o verbo escolher deriva das partes: es- + colher. Embora saibamos que ambos os verbos remetam a uma noção de sujeito consciente, investigaremos como essa relação realmente se colocará na materialidade dos dizeres dos sujeitos entrevistados.

9 De acordo com Neves (2008), o deslocamento é "algum movimento que retira o sujeito de uma determinada posição enunciativa para outra, não necessariamente significando que houve mudanças, mas sim algum desvio, alguma desarticulação, ou desprendimento de certas representações, para até mesmo voltar a elas de outro modo ou para dar lugar a outras" (NEVES, 2008, p.26).

10 Para o sociólogo Pierre Bourdieu (2007), o bem simbólico é um objeto qualquer, seja ele artístico ou cultural, que recebe atribuições mercantis de acordo com as leis do mercado e é configurado como uma mercadoria, tendo seu próprio grupo de consumidores e de produtores.

11 LEITE, N. Entre o conformismo e a ruptura: posicionamentos discursivos de professores de língua estrangeira em educação de jovens e adultos. 127 f. Dissertação - Universidade Federal de Minas Gerais, Belo Horizonte, 2013.

\section{Referências}

ANDRADE, E. R. Entre o desejo e a necessidade de aprender línguas: a construção das representações de língua e de aprendizagem do aluno-professor de língua inglesa.2008. 278 f. Tese (doutorado em Linguística Aplicada) Universidade Estadual de Campinas, São Paulo, 2008.

ARROYO, M. A educação de jovens e adultos em tempos de exclusão. In. Alfabetização e Cidadania. São Paulo: Rede de apoio à Ação Alfabetizadora do Brasil (RAAAB), n.11, abril 2001.

BELLO, P. Paulo Freire e uma nova filosofia para a educação.

http://br.geocities.com/maeutikos/pdfspedagogia/PAULO FREIRE.DOC, 1993a. Acesso em: 22/06/2012.

BOURDIEU, P. O poder simbólico. Tradução Fernando Tomaz, 10. ed. Rio de Janeiro: Bertrand Brasil, 2007.

DIAS, L. F. O adjetivo na formação nominal: uma abordagem enunciativa. Web-Revista Discursividade: Estudos Lingüísticos, v. 9, p. 10, 2012.

DUFOUR, D. R. A arte de reduzir as cabeças. Rio de Janeiro: Cia de Freud, 2005. 
FERNANDES, C. A. Discurso e Sujeito em Michel Foucault. 1. ed. São Paulo: Intermeios, 2012. v. 1. $106 \mathrm{p}$.

FERRARO, A. R. Alfabetismo e níveis de letramento no Brasil: o que dizem os censos. Educação \&Sociedade. Vol 23, n. 81, dez. 2002.

FOUCAULT, M. A arqueologia do saber. 3. ed. Tradução de Luiz Felipe Baeta Neves. Revisão de Lígia Vassalo. Petrópolis: Vozes; Lisboa: Centro do Livro Brasileiro, 1987.

FREUD, S. O mal-estar na civilização. In: Obras Completas, vol. XXI. 1 CDROM.1930.

GARCIA-ROZA, L.A. Introdução à metapsicologia freudiana. Sobre as afasias. O projeto de 1895 . Rio de Janeiro: Jorge Zahar, 1991.

GRIGOLETTO, M. Um dizer entre fronteiras: o discurso de professores e futuros professores sobre a língua inglesa. Trabalhos em Linguística Aplicada. Campinas: Unicamp, nº 41, p. 39-50, Jan.-Jun., 2003.

HADDAD, S.; DI PIERRO, M.C. Escolarização de jovens e adultos. Revista Brasileira de Educação, São Paulo, n. 14, p. 108-130, 2000.

HADDAD, S.; DI PIERRO, M. C. Uma visão da história da escolarização de jovens e adultos no Brasil. São Paulo: Ação Educativa. (mimeo). (Publicado em inglês como A historical overview of adult formal education in Brazil. In: CASTRO, R. V.de, SANCHO, A. V.; GUIMARÃES, P. (Eds.). Adult Education: new routes in a newlandscape. Braga: University of Minho. 2006. p. 231-270.)

JANNUZZI, G. M. Confronto Pedagógico: Paulo Freire e MOBRAL. São Paulo, Ed. Cortez, 1987.

KEHL, M. R. Lugares do feminino e do masculino na família. In: A Criança na Contemporaneidade e a Psicanálise. Vol. I Família e Sociedade: Diálogos Interdisciplinares. Comparato e Monteiro (orgs.) São Paulo: Casa do psicólogo, 2001.

LACAN, J. O seminário, livro 23: o sinthoma. Rio de Janeiro: Jorge Zahar, 2005.

MACHADO, M. M. A prática e a formação de professores na EJA: uma análise de dissertações e teses produzidas no período de 1986 a 1998. In: REUNIÃO ANUAL DA ANPED, 23, 2000, Associação Nacional de Pós-graduação e Pesquisa em Educação, Caxambu, 2000. Anais (Edição eletrônica).

MASCIA, M. Representações identitárias da EJA: "lugar de todos" e "lugar de ninguém". In: IX CONGRESSO LATINO-AMERICANO DE ESTUDOS DO DISCURSO ALED. Anais Belo Horizonte: UFMG, 2011.

MOREIRA, A.; KRAMER, S. Contemporaneidade, educação e tecnologia. Educação \& Sociedade, v. 28, p. 1037-1057, 2007.

NETTO, A. Tramas da subjetividade no espaço entre-linguas: narrativas de professores de lingua portuguesa em contexto de imigração. $243 \mathrm{f}$. (Doutorado em Linguística Aplicada) Instituto de Estudos da Linguagem, Universidade Estadual de Campinas, Campinas, 2008.

NEVES, M. S. O processo identificatório na relação professor-aluno na aprendizagem de língua estrangeira. In: MAGALHÃES, I.; CORACINI, M. J.; GRIGOLETTO, M. (Org.) Práticas Identitárias: língua e discurso. São Carlos: Claraluz, 2006. p. 4556.

NEVES, M. S. Identificações subjetivas no discurso sobre avaliação de aprendizagem após um curso de Educação Continuada. Horizontes (EDUSF), v. 26, p. 21-29, 2008.

NEVES, M. S. O acontecimento da gravidez na vida de uma jovem empregada doméstica como reprodução de um paradigma edípico. In: GUERRA, Vania Maria Lescano; ENEDINO, Wagner Corsino; NOLASCO, Edgar Cézar. (Org.). Estudos de linguagens: diversidade e ensino. 1ed. São Carlos: Pedro \& João Editores, 2012, v. 1, p.7586.

ORLANDI, E. Análise de Discurso: princípios e procedimentos. Campinas: Pontes, 2002.

ORLANDI, E.P. Interpretação e autoria: leitura e efeitos do trabalho simbólico. Rio de Janeiro, RJ: Vozes, 1996.

PÊCHEUX, M. $O$ discurso: estrutura ou acontecimento. Campinas: Pontes, 2006. 
ROUDINESCO, E., \& PLON, M. Dicionário de Psicanálise. Rio de Janeiro: Jorge Zahar,1998.

SANTOS, R. Genealogia e Governamentalidade em Michel Foucault. Belo Horizonte: UFMG, 2010.

(Dissertação de Mestrado)

SOARES, L. J. G. As políticas de EJA e as necessidades de aprendizagem dos jovens e adultos. In: RIBEIRO, Vera Masagão (org.). Educação de jovens e adultos: Novos leitores, novas leituras. Campinas: Mercado de Letras: Associação de Leitura do Brasil-ALB; São Paulo: Ação Educativa,
(Coleção Leituras no Brasil). p. 201-224, 2001.

SOUZA, M.A. Educação de jovens e adultos. Curitiba: IBPEX, 2007.

VEIGA-NETO, A. Foucault e a Educação. Belo Horizonte: Autêntica, 2003.

VÓVIO, C. L. Entre discursos. Sentidos, práticas e identidades leitoras de alfabetizadores de jovens $e$ adultos. 2007. $304 \mathrm{f}$. Tese (doutorado em Linguística Aplicada) - Universidade Estadual de Campinas.

\section{Sobre as autoras}

Natália Costa Leite: Faz parte do quadro efetivo de professores de Língua Inglesa do Ensino Básico, Técnico e Tecnológico do CEFET-MG e é doutoranda em Linguística Aplicada do Programa de Estudos Linguísticos (POSLIN).

Maralice de Souza Neves: Professora Associada da Faculdade de Letras da UFMG, docente e pesquisadora do Programa de Estudos Linguísticos (POSLIN) na área de Linguística Aplicada.

Recebido em setembro de 2016.

Aprovado em dezembro de 2016. 